\title{
Aktualisasi Nilai-Nilai Astha Brata Untuk Pengembangan Jiwa Kepemimpinan Generasi Z
}

\author{
Sutina \\ Universitas Sebelas Maret \\ sutinaaa8@student.uns.ac.id
}

Article History

received $1 / 9 / 2021$

revised $1 / 10 / 2021$

accepted 1/11/2021

\begin{abstract}
A government has several leadership traits, one of which is the leadership trait that comes from Java, namely Asta (Astha) Brata. Etymologically comes from Sanskrit, Asta means eight; and Brata: means practice or guidelines, in essence it contains eight teachings of leadership behavior which are symbolized by the attributes of the gods of nature, namely: sky, sun, wind, water, ocean, moon, stars, and fire. The current generation is still many who do not know the importance of the values contained in the teachings of Astha brata. This paper aims to manifest the values of Astha Brata for the development of the leadership spirit of Generation Z. This article uses a literature study method which will then be analyzed in a qualitative descriptive manner. The results carried out in the literature study stated that the leadership values in the teachings of Astha Brata can be manifested in the development of the leadership spirit of generation $Z$.
\end{abstract}

Keywords: Actualization, Leadership, Astha Brata, Z Generation

\begin{abstract}
Abstrak
Sebuah pemerintahan terdapat beberapa sifat kepemimpinan salah satunya ialah sifat kepemimpinan yang berasal dari Jawa yaitu Asta (Astha) Brata. Secara etimologis berasal dari bahasa Sansekerta, Asta berarti delapan; dan Brata: berarti laku atau pedoman, pada intinya memuat delapan ajaran perilaku kepemimpinan yang disimbolisasikan dengan sifat-sifat dewa alam, yaitu: langit, matahari, angin, air, samudra, bulan, bintang, dan api. Generasi saat ini masih banyak yang belum mengetahui pentingnya nilai-nilai yang terdapat dalam ajaran Astha brata. Tulisan ini bertujuan untuk memanifestasikan nilai-nilai Astha Brata untuk pengembangan jiwa kepemimpinan generasi Z. Artikel ini menggunakan metode studi literatur yang kemudian akan dilakukan analisis secara deskriptif kualitatif. Hasil yang dilakukan dalam studi literatur menyebutkan bahwa nilai-nilai kepemimpinan dalam ajaran Astha Brata dapat dimanifestasikan dalam pengembangan jiwa kepemimpinan generasi Z.
\end{abstract}

Kata kunci: Aktualisasi, Kepemimpinan, Astha Brata, Generasi Z

Social, Humanities, and Education Studies (SHEs): Conference Series https://jurnal.uns.ac.id/shes

p-ISSN 2620-9284

e-ISSN 2620-9292 


\section{PENDAHULUAN}

Selama kurun waktu satu dekade terakhir ini, Indonesia tengah mengalami fenomena transisi demografi. Kondisi ini terindikasi dari hasil sensus penduduk pada tahun 2000 yang memberikan fakta signifikan bahwa program KB (Keluarga Berencana) yang dilaksanakan oleh pemerintah dan masyarakat Indonesia pada waktu yang lalu memberi dampak yang sangat positif (Maryati, 2015).

Di Indonesia bonus demografi akan dicapai kira kira di tahun 20202035. Indonesia sebagai Negara dengan jumlah penduduk kurang lebih 237 juta jiwa (Sensus Pendududk 2010) adalah negara urutan no 4 di dunia dalam jumlah penduduknya. Struktur penduduk Indonesia mulai berubah dari jumlah penduduk muda( $<15$ tahun) yang banyak menuju jumlah penduduk produktif (15-64 tahun) yang banyak (Dewi dkk, 2018). Fenomena tersebut akhinya banya melahirkan batasanbatasan jenjang generasi yang akan menghadapi dan menjalani bonus demografi tersebut.

Salah satu generasi yang saat ini seharusnya sedang mempersiapkan diri untuk mengahadapi bonus demografi tersebut ialah generasi Z. Generasi Z ialah generasi yang sangat erat dengan kemajuan teknologi saat ini. Karakteristik dari generasi Z ialah generasi yang benar-benar lahir ketika teknologi sudah ada (Rastai, 2018). Generasi $Z$ yang berada pada era kemajuan teknologi harus dibekali dengan berbagai kemampuan dan sikap yang nantinya akan membantu dan menjaga mereka dari berbagai ancaman penggunaan teknologi agar siap menjadi pemimpin masa depan.

Kepemimpinan generasi selanjutnya sangat berpengaruh kepada kemajuan bangsa. Mempersiapkan generasi penerus bangsa terutama generasi $Z$ yang telah mengenal teknologi akan menajadi tugas bagi semua kalangan, baik orang tua, pendidik dan lembaga pendidikan. Nilai-nilai kepemimpinan harus ditanamkan kepada generasi yang saat ini sedang menghadapi kemajuan teknologi serta menjadi bekal saat menghadapi bonus demografi kelak. Dalam tulisan ini akan membahas salah satu ajaran mengenai kepemimpinan yang dapat membekali generasi $Z$ dan menanamkan nilai-nilainya yaitu ajaran Astha Brata yang merupakan salah satu ajaran mengeanai jiwa pemimipin yang baik dalam suku Jawa.

\section{Kepemimpinan}

\section{KAJIAN TEORI}

Kepemimpinan sering disebut sebagai nilai atau sisi yang terdapat dalam diri individu. Saat ini fenomena kepemimpinan sering disebut sebagai fenomena kolektif, yang terjadi secara merata dan terwujud karena adanya interaksi sesama individu (McCauley \& Paulus, 2020).

Teori mengenai kepemimpinan juga disampaikan oleh Katz dan Kahn (Wibowo, 2011) yang diartikan sebagai tiga kelompok besar dalam diri individu yang bersifat mendasar yaitu "sebagai sebuah atribut dari suatu kedudukan, sebagai suatu karakteristik individu serta sebagai perilaku".

\section{Generasi Z}

Jika sebelumnya kita hanya mengenal generasi tua dan generasi muda yang didasari oleh tahun kelahiran serta perasaan senasib dalam pengalaman perjalanan sejarah, generasi kini berkembang dalam kategori baby boomers, generasi $X$ (tahun lahir antara 1961-1980), generasi $Y$ (tahun lahir 1990- 1995), dan generasi Z (19952010). Pengelompokkan ini adalah pengelompokan berdasarkan kesamaan rentang tahun lahir, lokasi, serta peristiwa-peristiwa yang memengaruhi secara signifikan kehidupan kelompok tersebut (Christiani \& Ikasari, 2020)

Pola pikir generasi $Z$ yang terbuka dan menerima perbedaan di sisi lain membuat mereka kesulitan mendefinisikan dirinya sendiri. Jika generasi sebelumnya mendefinisikan dirinya berdasarkan gender, ras, agama, dan orientasi seksual, 
generasi $Z$ tidak menjadikan hal tersebut sebagai indikator. Mereka bahkan menggunakan selebgram sebagai pembelajaran bagaimana cara mendefinisikan dirinya. Generasi ini kemudian lebih suka menggabungkan banyak hal seperti komponen identitas dan pandangan yang dianggap menarik. Dari hal itu kemudian mereka membuat identitasnya sendiri (Rasati, 2018).

\section{Ajaran Astha Brata}

Pada awalnya ajaran Asta Brata memuat pemaparan sifat dewa alam (Manawa Dharmacastra) kemudian berubah menjadi sifat atau watak alam saja (Lakon Wahyu Makutha Rama), yang kemudian lebih banyak digunakan sebagai acuan dalam pementasan wayang saat ini. Selain itu, temuan analisis isi menunjukkan adanya overlapping atau saling tumpang tindih sifat atau nilai ajaran pada masing-masing teks.

Berikut ini merupakan definisi operasional dalam delapan sikap utama yang harus dimiliki oleh seorang pemimpin (As'ad dkk, 2011)

\begin{tabular}{ll}
\hline \multicolumn{1}{c}{ Watak } & \multicolumn{1}{c}{ Definisi operasional } \\
\hline Matahari & Pemimpin memiliki sifat berhati-hati dalam membimbing \\
& bawahannya. Pemimpin mampu memberikan dorongan energi \\
& kepada para bawahan secara perlahan, yang tanpa disadari \\
& akan membimbing bawahan menjalankan tujuan bersama. \\
Angin & Pemimpin memiliki sifat teliti ketika turun langsung \\
& memperhatikan atau mengawasi kinerja semua bawahan. \\
& Pemimpin harus berada dekat dengan bawahan tanpa \\
& membedakan statusnya. \\
Bulan & Pemimpin memiliki sifat periang yang mampu menyenangkan \\
& hati para bawahannya. Pemimpin mampu memberikan motivasi \\
& kepada para bawahan agar performa kinerjanya meningkat. \\
Api & Pemimpin memiliki sifat tegas dalam memerintah, terutama saat \\
& memberikan hukuman pada bawahan yang melakukan \\
& kesalahan. Pemimpin harus berani mengambil keputusan untuk \\
& menghukum bahkan mengeluarkan bawahan yang bersalah \\
& dalam kelompok. \\
& Pemimpin memiliki sifat murah hati dan adil terhadap semua \\
Bumi & pengikutnya. Pemimpin bersikap adil dengan memberikan \\
& penghargaan bagi para bawahan yang berprestasi tanpa \\
& membedakan statusnya. \\
& Pemimpin memiliki sifat mampu memberi nilai tambah keilmuan \\
& kepada para bawahannya. Pemimpin harus memiliki bekal \\
& keluasan pengetahuan atau kompetensi yang dapat diajarkan \\
Langit & Pepada para bawahan \\
& Pemimpin memiliki sikap terbuka dan mampu menampung \\
& aspirasi dari para bawahannya. Pemimpin hendaknya bersikap \\
& bijak dalam menyikapi setiap kritik dari bawahan. \\
& Pemimpin memiliki sifat percaya diri dalam memegang teguh \\
prinsip yang diyakininya. Prinsip kuat yang dimiliki pemimpin \\
adalah pedoman bawahan dalam bekerjasama mencapai \\
tujuan.
\end{tabular}

\section{METODE}

Penelitian ini adalah penelitian literatur. Literatur yang digunakan sebagai sumber adalah literatur yang akan dihubungkan dengan masalah yang ingin diteliti yaitu 
mengenai aktualisasi nilai-nilai astha brata untuk pengembangan jiwa kepemimpinan generasi $Z$.

\section{HASIL DAN PEMBAHASAN}

Perkembangan dan kemajuan suatu bangsa bergantung pada penerus bangsa, terutama genrasi muda. Penanaman nilai dan karakter harus tetap dilakukan agar dapat melahirkan genarsi pemimpin yang berbudi luhur dalam mengurus pemerintahan.

\section{Penaman Nilai-Nilai ajaran Astha Brata}

Generasi Z yang sudah memilki kemampuan dan sikap yang terbuka terhadap dunia luar harus dibekali dengan nilai-nilai sikap kepemimpinan yang terkandung dalam ajaran Astha Brata. Nilai tersebut dapat membantu generasi muda dalam menyikapi setiap permasalah yang akan dihadapi dalam proses pembangunan negara. Banyak sekali generasi muda terutama generasi $Z$ yang saat ini belum mengetahui apa saja delapan sifat utama dalam ajaran Astha Brata. Penanaman nilai tersebut dapat dilakukan dengan berbagai cara sebagai berikut:

a. Pendekatan dalam dunia pendidikan

Dunia pendidikan yang dimaksud ialah dengan menunjukkan bentuk delapan ajaran tersebut melalui keterlibatan langsung pendidik di sekolah seperti kepengurusan staf sekolah, cerminan seorang pendidik terutama pejabat sekolah harus memancarkan nilai-nilai Astha Brata.

\section{b. Pendekatan dalam Pembelajaran}

genarasi Z yang saat ini dengan rentan 8-23 tahun tentu saja masih banyak yang menginjak dunia pendidikan. Dalam hal itu pendidik harus memanfaatkan peluang tersebut dengan memasukkan nilai-nilai Astha Brata dalam proses belajar melalui pendekatan pembelajaran, metode pembelajaran serta model pembelajaran.

\section{Nilai Astha Brata Sebagai Perisai perkembangan Teknologi}

Menghadapi kondisi perkembangan teknologi yang sudah berkembang pesat tentu saja menjadikan fenomena ini seperti "pisau bermata dua". Terdapat keuntungan dan ancaman. Tentu saja sudah banyak kita ketahui bahwa keuntungan perkembangan teknologi sudah banyak dirasakan saat ini begitu juga ancamannnya yang sudah mulai terasa. Generasi $Z$ yang saat ini sudah mahir dalam menggunakan teknologi saat ini masih banyak sebagian besar dari mereka hanya sekedar menjadi penonton dan meniru hal-hal yang diperlihatkan melalui teknologi. Disinilah letak pentingnya nilai-nilai Astha Brata, bahwa setiap individu harus mampu menjadi pemimpin dalam skup terkecil yaitu dalam dirinya sendiri, menyerap sesuatu yang baik dan menjadi berilmu dapat mencerminkan nilai langit yang berarti bahwa pemimpin harus mampu memberikan nilai keilmuan untuk bawahannya..

\section{SIMPULAN}

Pengembangan jiwa kepemimpinan generasi $Z$ yang sedang menghadapi perkembangan teknolgi yang pesat perlu dilakukan agar dapat menjadikan generasi ini 
mampu menghadapi dan menjalani bonus demografi dimasa yang akan datang. Penanaman nilai-nilai Astha Brata yang merupakan ajaran mengenai jiwa kepemimpinan dapat menjadikan generasi Z mempunyai jiwa yangh luhur dan berbudi pekerti dengan menerapkan delapan sikap utama yang harus dimiliki oleh seorang pemimpin. Pengenalan dan pengenalan ini dapat dilakukan dengan penerapan di intansi terkait, seperti keluarga, lingkungan tempat tinggal, lingkungan penddikan serta lingkungan masyarakat secara luas.

\section{DAFTAR PUSTAKA}

As'Ad, Moh, Wahyu Jati Anggoro, and Mariana Virdanianty. (2011). "StudiEksplorasi Konstrak Kepemimpinan Model Jawa: Asta Brata." Jurnal Psikologi, 38, no. 2: 228-239.

Christiani, Lintang Citra, and Prinisia Nurul Ikasari. (2020). "Generasi Z Dan Pemeliharaan Relasi Antar Generasi Dalam Perspektif Budaya Jawa." Jurnal Komunikasi dan Kajian Media, 4, no. 2: 84-105.

Dewi, Sita, Dwi Listyowati, and Bertha Elvy Napitupulu. (2018). "Bonus Demografi Di Indonesia: Suatu Anugerah Atau Petaka." Journal Of Information System, Applied, Management, Accounting And Research, 2, no. 3: 17-23.

Maryati, Sri. (2015). "Dinamika pengangguran terdidik: tantangan menuju bonus demografi di Indonesia." Economica: Jurnal Program Studi Pendidikan Ekonomi STKIP PGRI Sumatera Barat, 3, no. 2: 124-136.

McCauley, Cynthia D., and Charles J. Palus. (2020). "Developing the theory and practice of leadership development: A relational view." The Leadership Quarterly : 101456.

Rastati, Ranny. (2018). "Media Literasi Bagi Digital Natives: Perspektif Generasi Z di Jakarta." Kwangsan, 6, no. 1: 286903.

Wibowo, Udik Budi. "Teori Kepemimpinan." Badan Kepegawaian Daerah Kota Yogyakarta [skripsi].[internet].[diunduh 26 September 2017]. Tersedia pada: http://staff. uny. ac. id/sites/default/files/tmp/C 20201113 (2011). 